\title{
CRIANÇA HOSPITALIZADA: MÃE E ENFERMAGEM COMPARTILHANDO O CUIDADO ${ }^{1}$
}

Neusa Collet ${ }^{2}$

Semiramis Melani Melo Rocha ${ }^{3}$

Collet N, Rocha SMM. Criança hospitalizada: mãe e enfermagem compartilhando o cuidado. Rev Latino-am Enfermagem 2004 março-abril; 12(2):191-7.

Nesta pesquisa objetivou-se verificar em que momento, em quais cuidados e de que forma as mães são incluídas na assistência à criança hospitalizada e verificar como acontece a negociação dos cuidados entre a equipe de enfermagem e mães. A pesquisa de campo foi realizada por meio da observação participante do cotidiano da assistência, em uma unidade pediátrica hospitalar e entrevistas com mães e equipe de enfermagem. A inclusão da mãe nos cuidados do filho tem acontecido de forma sutil. A mãe tem assumido procedimentos que eram de competência da enfermagem, concentrando informações sobre o processo terapêutico. A falta de um projeto terapêutico coletivo sob a perspectiva do cuidado centrado na família é um dos óbices ao envolvimento da mãe na assistência. Os resultados demonstram que as relações entre mães e equipe de enfermagem mostram-se complexas e permeadas pelo exercício do poder, sendo necessária a busca da construção do cuidado compartilhado.

DESCRITORES: criança hospitalizada; enfermagem pediátrica; negociação

\section{HOSPITALIZED CHILD: CARE SHARING BETWEEN} MOTHER AND NURSING

This research aimed to verify at what moment, in what kinds of care and in what way mothers are included in care to the hospitalized child and to verify how care is negotiated between nursing team and mothers. The field research was carried out through participant observation of everyday care at a pediatric hospital unit, as well as interviews with mothers and the nursing team. The inclusion of the mother in care has taken place in a subtle way. The mother has taken on procedures that had been part of Nursing competence before, concentrating information on the therapeutic process. The lack of a collective therapeutic project from the perspective of family-centered care is one of the obstacles to the involvement of mothers in care. Results demonstrate that the relation between mothers and the nursing team reveal to be complex and influenced by the exercise of power, which results in the need to construct shared care.

DESCRIPTORS: hospitalized child; pediatric nursing; negotiation

\section{NIÑO HOSPITALIZADO: MADRE Y ENFERMEROS COMPARTIENDO SU CUIDADO}

Este estudio tiene el objetivo de verificar el momento, los cuidados y las formas que las madres han incluido en la atención a los niños hospitalizados y verificar la negociación de los cuidados entre el equipo de enfermeros y las madres. El estudio de campo fue realizado por la observación del cotidiano de la atención en una unidad de pediatría de un hospital y entrevistas con las madres y el equipo de enfermeros. La inclusión en la atención de las madres a sus hijos se da sutilmente. Las madres han asumido procedimientos que pertenecen al equipo de enfermeros, reuniendo informaciones sobre el desarrollo del proceso terapéutico. La falta de un proyecto terapéutico colectivo con la atención centrada en la familia ha sido uno de los obstáculos para la participación de las madres en el cuidado de sus hijos. Los resultados demuestran que las relaciones que comprometen las madres y equipos de enfermeros son complejas y permedadas por el ejercicio del poder, haciéndose necesaria la construcción de un proyecto de cuidado compartido.

DESCRIPTORES: niño hospitalizado; enfermería pediátrica; negociación

\footnotetext{
${ }_{1}^{1}$ Parte da tese de doutoramento em enfermagem: Collet N. Criança hospitalizada: participação das mães no cuidado, Escola de Enfermagem de Ribeirão Preto, da Universidade de São Paulo, 2001; ${ }^{2}$ Enfermeira, Doutor em Enfermagem, Docente da Universidade Estadual do Oeste do Paraná, e-mail: ncollet@certto.com.br; ${ }^{3}$ Enfermeira, Professor Titular da Escola de Enfermagem de Ribeirão Preto, da Universidade de São Paulo, Centro Colaborador da OMS para o desenvolvimento da pesquisa em enfermagem, e-mail: smmrocha@eerp.usp.br
} 
APRESENTAÇÃO

$\boldsymbol{A}$ permanência dos pais em período integral no ambiente hospitalar, sua participação no cuidado e a natureza da relação entre crianças, pais e profissionais, têm desencadeado novas formas de organização da assistência à criança hospitalizada. Nessa perspectiva, 0 foco é ampliado. Torna-se necessário dirigir o olhar para a família como objeto do cuidado, num processo de produção de relações e intervenções, para além do atendimento clínico.

Essa possibilidade de assistência foi efetivamente trazida para o hospital a partir da publicação do Relatório Platt ${ }^{(1)}$, na Inglaterra. No Brasil, a preocupação com a permanência dos pais no hospital passou a se tornar mais efetiva após a promulgação da Lei no 8.069 , de 13 de julho de 1990, que regulamenta o Estatuto da Criança e do Adolescente (ECA). Em seu Artigo 12, o ECA dispõe que "os estabelecimentos de atendimento à saúde deverão proporcionar condições para a permanência em tempo integral de um dos pais ou responsável, nos casos de internação de criança ou adolescente",(2).

A inserção de um acompanhante e seu envolvimento no processo terapêutico torna fundamental a compreensão da dinâmica das relações entre os agentes que prestam o cuidado, pois aparecem questões não bem definidas na assistência à criança hospitalizada. É importante estar alerta às novas necessidades que vão sendo criadas nesse espaço e que envolvem a forma de organização das unidades pediátricas como um todo. Essas não são simples alterações no projeto e na caracterização da unidade ou no tipo de facilidades dadas à família, mas também nas atitudes dos profissionais de saúde quanto ao envolvimento dos pais no cuidado à criança hospitalizada, na relação que esses estabelecem com os pais, na qualidade da assistência, enfim, alterações que envolvem a dinâmica do trabalho de uma forma geral.

A perspectiva de levar os pais para dentro do hospital traz consigo alterações nas relações de trabalho estabelecidas no ambiente hospitalar. Eles foram encorajados a ficar com os filhos durante a hospitalização, tornando-se mais um dos agentes que tomam parte no processo de cuidado, embora não tivesse sido efetivamente considerado como pais e enfermagem poderiam experenciar essa nova convivência. Atualmente, reconhece-se a importância dos pais no hospital, contudo, mostra-se igualmente importante a discussão de sua participação no cuidado ao filho hospitalizado.
Esta investigação, portanto, tem como objetivo verificar em que momento, em quais cuidados e de que forma as mães são incluídas na assistência à criança hospitalizada e como acontece a negociação dos cuidados entre a equipe de enfermagem e as mães.

\section{QUADRO TEÓRICO}

Para construção do quadro teórico de nosso estudo definimos alguns conceitos com a finalidade de orientar a análise dos resultados.

O hospital foi apreendido como instrumento terapêutico no final do século XVIII. "A consciência de que o hospital pode e deve ser um instrumento destinado a curar aparece claramente em torno de 1780"(3). Anteriormente a esse período, o hospital era o local onde os pobres, moribundos, doentes e inválidos ficavam. Com a introdução da tecnologia e cientificidade médica, o hospital começa a ser visto como dispositivo do cuidado médico ${ }^{(4)}$.

No hospital encontramos, além da sua estrutura formal de funcionamento, áreas de interação e trabalho, nem sempre visíveis, organizadas de acordo com normas e regras que não seguem a linha de autoridade e direção requerida pela administração burocrática ${ }^{(5)}$. Enquanto a estrutura formal envolve regras oficiais que orientam os comportamentos considerados apropriados aos objetivos específicos da organização, a estrutura informal diz respeito aos valores e aos padrões de comportamento, independentes das regras formais, resultantes das relações interpessoais entre os membros da organização ${ }^{(5)}$. Ao analisar as relações entre pais e enfermeiros, Darbyshire ${ }^{(6)}$ aponta o poder da disciplina que está presente nas atitudes dos enfermeiros e dos pais, nos olhares controladores, podendo exercer momentos de dominação-subordinação na relação.

Pais e equipe de enfermagem têm pelo menos um objetivo comum, o restabelecimento da saúde da criança. Portanto, a possibilidade do desenvolvimento de ações que permitam a produção de um maior grau de autonomia de ambos na relação não pode ser negado.

Partindo do ponto de vista de que a estrutura formal das organizações hospitalares depende, em grande parte, dos vários tipos de negociações que seus agentes estabelecem entre si, em diferentes áreas de trabalho e interação, para manter em funcionamento as atividades 
diárias da instituição, a organização do processo de cuidado na unidade pediátrica não é diferente.

A teoria de ordem negociada, usada pela sociologia, tem como conceito operativo central a "negociação" entendida como uma das formas de ação que os indivíduos desenvolvem para a concretização dos seus objetivos ${ }^{(7)}$. O princípio fundamental desse conceito é que as sociedades estão num permanente processo de organização e reorganização e que isso é produzido pelos indivíduos nos processos interativos que são constantemente modificados, refeitos, sustentados, defendidos em processos de negociação. $\mathrm{Na}$ instituição hospitalar, há vasta e variada gama de negociações, sendo importante ser considerada na análise a relação das regras com os processos "negociativos", os territórios privilegiados para realização desses processos e os tipos e formas possíveis de participação dos não-profissionais nas negociações ${ }^{(5)}$.

A unidade pediátrica hospitalar é um lugar que reúne uma diversidade de agentes, com diferentes formações, posições hierárquicas e localizações na divisão do trabalho. Como o recorte do objeto deste trabalho é a questão da negociação do cuidado entre a enfermagem e as mães da criança hospitalizada, parece-nos importante trazer para esta discussão o conceito de ordem negociada, para verificar em que medida e de que forma as mães são incluídas nos cuidados prestados à criança, bem como quem define a extensão dessa participação nos diferentes momentos do processo de cuidado. É sempre problemático perceber quais as regras que existem, a quem e como se aplicam. Acreditamos que, ao estabelecer relações, mães e enfermagem criam regras informais para regular as ações e situações nas quais as regras formais não dão conta, num permanente processo de reconstrução e cruzamento das regras formais com as informais. Trata-se da relação complexa estabelecida entre os processos negociativos diários, potencialmente geradores de conflitos e tensões, e as regras e políticas de atenção à saúde da criança, presentes no hospital.

Em pediatria, tem-se buscado mudança na modalidade da assistência, passando daquela cujo foco é a criança e sua patologia para aquela centrada na família $^{(8)}$. A principal meta do cuidado à criança é sempre centrado na família, considerada a unidade primária do cuidado $^{(9)}$. Essa concepção não desconsidera toda a sistematização construída até o momento, mas a amplia, incluindo a família na perspectiva do cuidado, capacitando melhor a enfermagem a entender o indivíduo e a prestar assistência.

\section{ABORDAGEM METODOLÓGICA}

Trata-se de um estudo de caso ${ }^{(10)}$, com descrições detalhadas de situações com o objetivo de compreender os indivíduos em seus próprios termos ${ }^{(11)}$.

A coleta de dados empíricos foi realizada em uma unidade de alojamento conjunto pediátrico de um hospital público estadual do interior do Estado do Paraná. Os sujeitos da pesquisa foram mães que vivenciavam a experiência de acompanhar a hospitalização de um filho. A seleção desses sujeitos foi realizada diariamente, por meio do livro de registros de internação de pacientes, sendo selecionada a última admissão ocorrida na unidade. Também participaram da pesquisa os membros da equipe de enfermagem que atuam na unidade em estudo, incluindo as duas enfermeiras que trabalham na unidade, dois auxiliares de enfermagem dos turnos matutino e vespertino e um de cada período noturno*. Todos os sujeitos da pesquisa assinaram um Termo de Consentimento Livre e Esclarecido, a fim de que pudéssemos utilizar os dados para análise, conforme especificado na Resolução 196/96 ${ }^{(12)}$. O projeto de pesquisa foi submetido à apreciação do Comitê de Ética em Pesquisa da Escola de Enfermagem de Ribeirão Preto da Universidade de São Paulo, o qual foi aprovado e, após consentimento da Direção Geral do hospital, deu-se início à coleta dos dados empíricos.

Para a coleta dos dados empíricos foram utilizadas as técnicas de observação participante, cujos dados foram registrados em diário de campo, e entrevistas com mães e equipe de enfermagem. Foram entrevistadas 23 mães, 7 auxiliares de enfermagem e 2 enfermeiras. Os dados coletados foram submetidos a pré-análise, exploração do material, tratamento dos resultados e interpretação ${ }^{(13)}$. Para interpretação, em primeiro nível, a fala dos sujeitos foi situada em seu contexto. A conjuntura sócioeconômica e política do grupo social entrevistado foi definida na fase exploratória da pesquisa. O segundo nível de interpretação emergiu a partir dos dados empíricos coletados.

* Turno noturno: $12 \mathrm{hx} 60 \mathrm{~h}$ 
Compreende a ordenação, classificação e análise final ${ }^{(13)}$. Como deste estudo participaram somente mães e nenhum pai, dentre os acompanhantes das crianças hospitalizadas, passaremos a utilizar o termo mães para nos referir à família e/ou acompanhante.

\section{RESULTADOS: A NEGOCIAÇÃO DO CUIDADO}

Com a permanência da família em período integral no hospital, emerge a necessidade de os profissionais criarem habilidades de conviver com a família em situação de doença ${ }^{(14)}$. Assim, a inserção da família na assistência à criança hospitalizada desencadeia nova forma de organização do trabalho da enfermagem, tendo em vista que a mãe passa a realizar muitos cuidados ao filho antes de competência da enfermagem, especialmente aqueles relacionados à higiene, alimentação e apoio emocional à criança.

A negociação entre mães e equipe de enfermagem, em relação aos cuidados a serem prestados à criança, durante seu período de hospitalização, não tem sido uma tarefa fácil nem para a equipe, que não tem claro qual seu novo papel nesse processo, nem para as mães, pois não sabem o que delas é esperado nas unidades de internação pediátricas. Assim, vale ressaltar os aspectos que chamaram nossa atenção pela forma como são conduzidos no cotidiano da assistência. Se nem a enfermagem tem clareza da atual condução da assistência, como são feitos os acordos entre mãe e equipe de enfermagem na divisão de tarefas ora estabelecida? Como se dá a negociação no processo de cuidar da criança hospitalizada?

Esse não é um tema fácil de ser identificado ou explicitado, pois os acordos são velados e não explícitos. Identificamos que as auxiliares de enfermagem acreditam que todas as mães já sabem que a elas cabe realizar determinados cuidados porque elas não perguntam às mães se querem ou não fazê-lo, tampouco se precisam de ajuda. A medicação via oral, por exemplo, é entregue na mão da mãe ou deixada sobre a mesa de cabeceira, com a seguinte informação: ...esse aqui é um remedinho pra ele (ela); depois você dá esse remédio aqui pra ele mãezinha (O24, p.81).

Não se preocupam se a mãe sabe fazer e, na maioria das vezes, não acompanham a administração feita pela mãe. Uma das enfermeiras afirma que existe um acordo implícito, não explícito (E1 p.8, E) em relação ao que é passado para a mãe fazer, e uma auxiliar de enfermagem diz que as mães sabem que terão que fazer alguns cuidados.

Eu acho que a mãe interna sabendo que ela vai cuidar da higiene e da alimentação, mesmo aquelas que internam pela primeira vez, porque quando uma mãezinha interna que eu estou cuidando eu falo: 'ó mãezinha, a senhora vai dar alimentação, vai dar o banho'. (...) Ela sabe que tem que dar o banho e se ela vai ficar junto com a criança será que daí ela vai pensar que a enfermagem também vai ter que dar o banho, vai trocar as fraldas? Eu acho que ela já sabe (E3, p.28, AE).

Esse é o acordo existente, a enfermagem vai passando para a mãe cuidados dessa natureza. Não estabelecem um diálogo com a mãe para tentar uma negociação na divisão do trabalho. A negociação não é feita de modo claro, mas é implícita. Os acordos não são abertamente discutidos, mas velados, a mãe se sente responsável e vai assumindo determinados cuidados. Quando perguntado como elas começaram a fazer os cuidados, geralmente respondiam que foi porque viram as outras mães fazendo, todavia, identificamos, durante as observações, que além de verem outras mães fazendo, a enfermagem, sutilmente, Ihes diz o que devem fazer. A mãe acredita que esse é seu dever por estar presente na assistência, por lhe ter sido "concedida" a permissão de estar em período integral no hospital com o filho. Em nenhuma oportunidade foi identificado algum tipo de crítica por parte das mães por estarem realizando os cuidados.

Tudo fica subentendido nessa relação. A partir do momento que a mãe adentra no mundo do hospital, não tem claro qual a natureza ou extensão de sua participação no cuidado, vai descobrindo no cotidiano da assistência ${ }^{(6)}$.

Existe cooperação na assistência, contudo, fica caracterizada uma relação entre enfermagem e mães mais de dominação-subordinação do que de colaboração, de co-participação no cuidado à criança hospitalizada.

A expectativa é de que as mães façam esses cuidados, porém, a enfermagem deixa vir à tona a confusão na qual está mergulhada, quando explicita a quem cabe determinar essa divisão de tarefas. Primeiro afirma que a enfermagem encaminha a mãe para fazer alguns cuidados, como dar o banho, e, logo a seguir, fala o contrário, que não foi a enfermagem que passou para a mãe fazer, mas a própria mãe 'automaticamente' começou a fazê-los.

A gente espera que a mãe faça isso, ao menos ela tem feito. Desde quando começou o alojamento conjunto a gente passou 
esses cuidados, aliás, ela, automaticamente, começou a fazer esses cuidados, não foi a gente que passou. O banho a gente deixou pra ela. Então, a parte de higiene ela mesma automaticamente já faz. Às vezes, têm algumas que a gente precisa falar: 'você tem que trocar, tem que fazer isso, tem que fazer aquilo' (E4, p.35, AE).

Quem determina o que deve ser feito é o pessoal do hospital, pois estão numa posição de controle. As mães aceitam, às vezes não concordam, mas acabam fazendo e não questionando, pois não estão numa posição de tomar a iniciativa de negociar os cuidados e não encontram estratégias para persuadir a equipe de enfermagem. Elas vêm fazer a medicação, assim no soro, trocar o soro, ver a temperatura, mas quando tem medicação na boca, inalação, essas coisas é a gente que faz (O24, p.80).

Ao ser questionada sobre quem define esta divisão de tarefas a auxiliar diz:

...nós mesmos. A gente sabe o que a mãe pode fazer. Por exemplo: eu não posso dar uma medicação endovenosa para a mãe fazer, nem seria o certo dar a medicação via oral para a mãe dar, mas isso a gente dá. Eu mesmo estou ali, eu tenho que medicar para ter certeza de que foi feito, que posso ficar segura. (...) A enfermagem estipula: isso a mãe não pode, isso a mãe pode, aliás, não tem quem estipula, as coisas são meio implícitas, vão acontecendo (E5, p.46, $A E)$.

A auxiliar de enfermagem não tem muita clareza desse processo. Primeiro afirma que é a enfermagem quem define a divisão de tarefas e estipula o que a mãe pode e o que não pode fazer, depois não fica tão segura de tal afirmação e percebe que não existe uma organização comum na forma de conduzir a assistência.

Já outra auxiliar afirma com segurança que é a equipe, pois é a equipe que fala: olha mãe, a alimentação, a troca de fraldas, o banho, esses cuidados a senhora que presta. $A$ equipe toda fala isso para as mães (E6, p.53, $A E$ ).

Há um impresso, que as mães deveriam receber na admissão, onde constam, entre outras informações, as atribuições das mães. Isso está escrito num panfletinho das normas e rotinas da pediatria que é entregue para as mães. Ali tem escrito o que ela deve fazer, mas, normalmente, algumas não cumprem, apesar de ali já estar determinado (E7, p.59, AE).

Apesar de todas essas formas pelas quais a mãe poderia ser informada sobre sua participação no cuidado, freqüentemente as mães ficam confusas e inseguras em relação ao que delas é esperado e/ou permitido fazer durante sua permanência no hospital. A negociação dos papéis entre pais e enfermagem é um dos fatores geradores de estresse ${ }^{(15)}$. Contudo, essa negociação é menos problemática, quando os enfermeiros são mais flexíveis e abertos a ela ${ }^{(16)}$.

A participação das mães na assistência está mais relacionada àqueles cuidados realizados em casa, como tarefas básicas da mãe, parecendo uma continuação e/ ou extensão para o hospital de sua prática diária no lar. Não se identificou um planejamento da assistência e de cuidados, devidamente articulado, com definição de quem o executaria. Não há iniciativa nem por parte da enfermagem nem por parte das mães para o estabelecimento de uma negociação nesse sentido.

Algumas mães realizam cuidados mais complexos, como administração de medicação e dieta por sonda nasogástrica. Isso ocorre, com maior freqüência, quando a criança continuará com sonda após a alta hospitalar. A justificativa é que a mãe está sendo treinada para continuar fazendo esse cuidado em casa.

Aparentemente, a divisão das tarefas é previamente determinada pela instituição e pelos profissionais, cabendo à mãe, a princípio, cumprir o que Ihe é determinado, pois está inserida num território que foge ao seu controle, ficando à mercê das decisões tomadas por outros. Porém, na medida em que vai participando, vai adquirindo o poder dado pela prática. Ao executar determinadas ações e por estar presente maior tempo com a criança, a mãe tem nas mãos certo poder, pois passa a ser a única pessoa que acompanha o processo diagnóstico-terapêutico de seu filho em sua totalidade. A autonomia das mães é expandida ou contraída diante das situações que vai vivenciando no hospital.

A unidade pediátrica, a partir da permanência de um acompanhante em período integral com a criança, sofre um processo de reorganização de suas práticas cotidianas, modificando a estrutura formal da organização hospitalar. O cuidado continua sendo realizado numa instituição burocratizada, com espaços definidos, com regras e regulamentos minuciosos que regem seu funcionamento, cuja divisão do trabalho define as posições hierárquicas da diversidade dos agentes que aí atuam. Contudo, em relação à negociação do cuidado entre equipe de enfermagem e mães, as regras formais são reconstruídas por meio de um cruzamento com as regras informais, criadas nas negociações, veladas ou explícitas, que vão sendo estabelecidas em situações singulares. Ao cuidar do filho hospitalizado, as mães trazem à cena dessa cadeia de regras suas crenças, saberes e 
experiências, desencadeando mudanças na estrutura formal da qual falamos. A mãe incorpora sob sua responsabilidade alguns cuidados e acaba assumindo sua obrigação. Eu acho que é a mãe que deve fazer, com certeza deve ser a mãe (OE27, p.86.; Eu acho que a mãe tem que fazer isso mesmo, está aqui que é pra cuidar do filho também (E20, p.65).

A responsabilização pela execução do cuidado tem sido passada para a mãe e a enfermagem tem dúvidas se essa forma de inclusão das mães é o melhor caminho para a construção da assistência à criança nesse novo contexto. Segundo a enfermeira, a partir do momento que a mãe recebe algum esclarecimento acerca do que deve fazer, a equipe "deixa por conta" dela, não se inteirando de como ela desenvolve os cuidados. A partir do momento que o pessoal sabe que foi falado (para as mães), simplesmente deixam correr, não tomam mais conhecimento do que está acontecendo, a mãe tem que se virar, elas (auxiliares) não acompanham mais (...) deixam por conta da mãe e daí não querem mais saber como que está acontecendo a coisa (E1, p.3, E).

A mãe não participa da tomada de decisões, mas está participando dos cuidados do filho. Contudo, a forma como vem se dando essa participação não contribui para a construção do cuidado compartilhado entre mães e enfermagem. Ao contrário, solidifica o distanciamento existente entre ambas e fortalece a execução do cuidado fragmentado, dividido em partes de acordo com o valor atribuído a cada cuidado. São passados às mães os cuidados considerados mais domésticos, o que ela já faz em casa e que não apresentam exigências de conhecimentos mais elaborados para desenvolvê-los. Esses são os cuidados menos valorizados pela enfermagem, logo, delega-os à mãe, pois no processo terapêutico não adquirem a mesma relevância atribuída a outras ações. Aparentemente, dá-se uma divisão entre trabalho intelectual e trabalho manual.

Esse é o modelo de assistência ora desenvolvido na unidade pediátrica do hospital em estudo. Essa prática está arraigada na hierarquia de poder, na resistência à mudança, em direção à construção de espaços que possibilitem uma conciliação entre mães e enfermagem.

\section{CONSIDERAÇÕES FINAIS}

Na medida em que as definições dos papéis vão sendo instituídas nas práticas assistenciais à criança hospitalizada, é possível identificar diferentes concepções do processo de participação das mães no cuidado entre os membros da equipe de enfermagem.

A proposta da permanência da mãe no hospital surgiu da necessidade da colaboração da mãe no processo de recuperação da saúde do filho, por meio do apoio emocional e segurança sentida pela criança por ter ao seu lado alguém de sua confiança ${ }^{(17)}$.

Neste estudo, verificamos que a enfermagem não se organizou para compartilhar com a mãe uma metodologia de assistência planejada, na qual não prevalecesse a simples divisão de tarefas, mas uma tomada de decisões baseada nas necessidades da criança e da mãe.

Compartilhar os cuidados com a mãe é desejável, porém observamos a existência de uma delegação sem co-participação. A enfermagem delegou tarefas e responsabilidades à mãe e se eximiu de seu principal papel. Assevera-se a fragmentação da assistência, não mais entre os profissionais de enfermagem, mas entre eles e as mães, dando indícios de desprestígio para a profissão.

Identificamos que o diálogo não faz parte dos instrumentos da enfermagem para negociar os cuidados com a mãe. Há uma atitude implícita, da mãe, em não interferir nos espaços cada vez mais delimitados desses agentes na unidade pediátrica. Por outro lado, há uma atitude omissa da enfermagem ao não explicitar os espaços e funções que são considerados parte do trabalho coletivo de diagnóstico e terapêutica, que cabe à mãe, a ela própria. Durante a hospitalização de uma criança, alguns cuidados que são do âmbito privado da família como alimentação, higiene, repouso, prevenção de acidentes domésticos, entre outros, passam a ser parte do plano assistencial de enfermagem, sob responsabilidade da instituição. Há uma dificuldade da enfermagem em fazer esse reconhecimento e tornar transparente para ela e para a mãe como lidar com a interseção entre o âmbito doméstico e o hospitalar e o terapêutico.

A mãe pode criar intervalos de autonomia na medida em que vai desenvolvendo e dominando um saber acerca dos cuidados hospitalares, pois tem como vantagem o conhecimento das singularidades do filho.

Atitudes de empatia na relação entre a enfermagem e as mães poderão criar um ambiente no qual elas se sintam mais seguras e fortalecidas para enfrentar a hospitalização do filho.

Utilizando os saberes técnicos e científicos e a 
estrutura formal da instituição como ponto de partida, os profissionais de enfermagem poderiam imprimir, na dinâmica do trabalho, um plano de cuidados compartilhado, no qual a equipe e os familiares teriam coresponsabilidades. Dessa forma, estaria sendo aberto um caminho para a emancipação e exercício da cidadania com respeito mútuo entre usuários e profissionais de saúde e seria superada a simples divisão aleatória de tarefas.

A enfermagem já possui um acervo de conhecimentos empíricos e teóricos que lhe permite, com

\section{REFERÊNCIAS BIBLIOGRÁFICAS}

1. Department of Health and Social Security (London). Central Health Services Council. The welfare of children in hospital: report of the committee. Her Majesty's Stationery Office. London; 1959.

2. Ministério da Saúde (BR). Estatuto da criança e do adolescente. Brasília (DF): Ministério da Saúde; 1991.

3. Foucault M. Microfísica do poder. $10^{\underline{a}}$ ed. Rio de Janeiro (RJ): Graal; 1992.

4. Pitta AMF. Hospital: dor e morte como ofício. 4aㅡ ed. São Paulo (SP): Hucitec; 1999.

5. Carapinheiro G. Saberes e poderes no hospital: uma sociologia dos serviços hospitalares. Porto (Portugal): Afrontamento; 1993.

6. Darbyshire P. Living with a sick child in hospital: the experiences of parents and nurses. London (Inglaterra): Chapman \& Hall; 1994.

7. Lopes NGM. A recomposição dos saberes, ideologia e identidades de enfermagem: estudo sociológico em contexto hospitalar. [dissertação]. Lisboa (Portugal): Instituto Superior de Ciências do Trabalho e da Empresa; 1994.

8. Ahmann E. Examining assumptions underlyng nursing practice with children and families. Pediatric Nurs 1998 Sep/ Oct; 23(5):467-9.

9. Pillitteri A. A framework for child health nursing. In: Child health nursing: care of the child and family. Philadelphia (USA): Lippincott; 1999. p.3-53.

10. Chizzotti a. Pesquisa em ciências humanas e sociais. São Paulo (SP): Cortez; 1991.

11. Goldenberg M. A arte de pesquisar: como fazer pesquisa qualitativa em ciências sociais. $2^{\underline{a}}$ ed. Rio de Janeiro (RJ): Record; 1998.

12. Comissão Nacional de Ética em Pesquisa. Conselho Nacional de Saúde (BR). Normas regulamentadoras de pesquisa envolvendo seres humanos. Resolução no 196/96 - CNS. Brasília (DF): Ministério da Saúde; 1996.

13. Minayo MCS. O desafio do conhecimento: pesquisa qualitativa em saúde. $2^{\underline{a}}$ ed. São Paulo (SP): Hucitec; 1993.

14. Rossato-Abéde LM, Angelo M. Crenças determinantes da intenção da enfermeira acerca da presença dos pais em unidades neonatais de alto risco. Rev Latino-am Enfermagem 2002 jan/dez; 10(1):48-54.

15. Hayes VE, Knox JE. The experience of stress in parents of children hospitalized with long-term disabilities. J Adv Nurs 1984; 9(4):333-41. segurança, negociar com a equipe e com os familiares um plano de assistência mais abrangente, que não se limite à consecução de técnicas. Assim, a enfermagem não deve se deixar levar por arranjos e acomodações imediatas ou por resistências à mudança, mas introduzir experiências que modifiquem sua prática em direção a uma assistência voltada às reais necessidades da criança e de sua família, envolvida no processo. A sensibilidade é necessária para percebermos os múltiplos determinantes que envolvem o cuidado à família.

16. Coyne IT. Partnership in care: parent's views of participation in their hospitalized child's care. J Clin Nurs 1995; 4:71-9.

17. Collet N, Oliveira BRG. Criança hospitalizada sem acompanhante: experimentando o sofrimento. Texto \& Contexto Enfermagem 1998; 7(2):255-67. 